\title{
010 FOAMS FOR GOR CONTROL - IMPROVED STABIITTY BY POLYMER ADDITIVES
}

MORTEN GUNNAR AARRA, PER ARNE ORMEHAUG and ARNE SKAUGE Norsk Hydro ASA, 5020 Bergen, Norway

\begin{abstract}
Displacement tests in sandstone cores have been applied to quantify formation of foam and the gas blocking ability of water continuous foams with polymer additives. The different chemical properties of polymers and their interactions with surfactants made it interesting to test both biopolymers and synthetic polymers. Low mobility foams were generated both in Berea and reservoir core material with AOS based foams. The formation of foam with alphaolefinsulfonate surfactant was little influenced by polymer additives as indicated by similar foam properties throughout the core. The gas blocking ability of the foams was improved with polymer.
\end{abstract}

\section{Introduction}

In a foam system gas is the discontinuous phase, separated by thin liquid films ${ }^{1}$. The result of foam formation in a porous media is a reduced gas mobility. Foam has been used to increase sweep efficiency and to reduce gas inflow caused by gas coning or gas flowing in high permeability streaks ${ }^{2}$. Lately, foam has received great interest as a gasblocking agent for high temperature and high pressure oil reservoirs ${ }^{3,6}$. Reducing gas oil ratio (GOR) is best achieved with low mobility, preferable stagnant foam.

From our previous publications $\mathrm{s}^{3,4}$ water continuos foams made from surfactants like alphaolefinsulfonates (AOS), have proved to form strong foams in reservoir sandstones in the presence of crude oil. Foams are not thermodynamic stable ${ }^{5}$, and will decay with time.

In this paper we have investigated the influence of polymer additives on the stability and gas blocking ability of water continuous foams made from AOS surfactants. Only a few papers have reported core flood results quantifying the effect of polymer enhanced foams ${ }^{6.8}$. From bulk experiments we have seen that addition of polymers seem to reduce the drainage of water from the foam lamellae. The validity of bulk foam experiments at ambient conditions can be questioned and the paper mainly focus on dynamic experiments at reservoir conditions. Core flood experiments have been nu both without oil and with residual oil saturation after primary gas injection. Both Berea and reservoir cores have been used. Foam was generated by co-injecting gas and surfactant solution. We have studied formation of foam, the gas blocking ability for various AOS - polymer combinations, and at different conditions foam quality (per cent of gas) and flow rates. In some experiments in-situ water saturation was monitored to investigate the foam quality within the porous media.

\section{Experimental}

The core material used in the experiment were $3,7 \mathrm{~cm}$ diameter cylindrical sandstone cores either outcrop Berea, $L=29$ and $44 \mathrm{~cm}$ and $\mathrm{Kw}=500-750 \mathrm{mD}$, or North Sea reservoir core, $\mathrm{L}=29$ and $91 \mathrm{~cm}$ and $\mathrm{Kw}=1,3$ and $1,7 \mathrm{D}$.

Four different types of core flooding experiments have been performed.

1) Foam formation and gas blocking, polymer enhanced foams, $40^{\circ} \mathrm{C}, \mathrm{S}_{\mathrm{o}}=0$, Berea cores $(\mathrm{L}: 29 \mathrm{~cm})$ Foam was generated by coinjection at $110 \mathrm{Bar}$, while the following gas injection was run at $130 \mathrm{Bar}$.

2) Foam formation and gas blocking, polymer enhanced foams, 70 or $100^{\circ} \mathrm{C}, \mathrm{S}_{\mathrm{agg}}$, reservoir core $(\mathrm{L}: 91 \mathrm{~cm})$. 
Foam formation was run at 290 Bar while the gas injection was run at $~ 310$ Bar. Both generation and gas injection were performed at 100 or $70^{\circ} \mathrm{C}$ with residual oil saturation after gas flooding $\left(S_{\text {org }} \sim 0.1 \mathrm{PV}\right.$ ) present. The core length was $91 \mathrm{~cm}$ and there were 6 pressure ports along the core.

3) Formation of foam at different flow rates, $100 \mathrm{bar}, 50^{\circ} \mathrm{C}, \mathrm{S}_{\mathrm{o}}=\mathrm{S}_{\mathrm{ong}}$, and Berea (L:29 and $44 \mathrm{~cm}$ ) Foam generation at different flow rates and foam qualities. Experiments were run in Berea cores at 100 Bar, $50^{\circ} \mathrm{C}$ and with oil present as $\mathrm{S}_{\mathrm{og}}$.

4. Foam quality, in-situ saturations, $30 \mathrm{Bar}$, ambient temperature, $\mathrm{S}_{\mathrm{o}}=0$, and reservoir cores (L:29cm)

Foam generation with measurement of in-situ saturations in the core. The experiments were run at 30 Bar, ambient temperature, using reservoir core, but without oil present.

All reported core experiments have been performed with an alphaolefinsulfonate (AOS) from Albright and Wilson (LSS 38/AS), molecular weight 328. This surfactant have been applied for gas blocking on the Oseberg field ${ }^{5}$. 18 different polymers added to AOS were tested in static bulk foam tests in a blender (polymix RW20 mixer). Three of the polymers; Xantan (Mw: $5^{*} 10^{6}$ ), polyvinylalcohol (PVA,

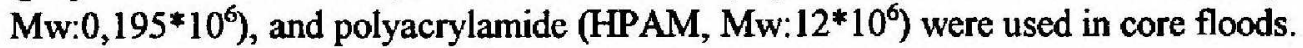

\section{Core flood test procedure.}

The cores were surrounded by a teflon and an aluminium foil inside a viton sleeve before mounting in the core holder. The cores consisted either of several core pieces, carefully machined to ensure good capillary contact, or one piece cores. The cores were evacuated and then saturated with brine. For the experiments where oil was present, water was drained to irreducible water saturation with a high viscous oil and exchanged with North Sca reservoir oil (that is methane saturated STO). The core was placed in a vertical position and a gravity stable primary gas (methane) injection was performed. The core was then placed in a horizontal position for all foam experiments.

Before starting the foam experiments approximately 2 pore volumes of surfactant solution was flooded through the cores. In most experiments the flow rate was about $40 \mathrm{ml} / \mathrm{h}$ and the foam quality $65 \%$. The fluids were recombined oil, methane, and brine $(36,000 \mathrm{ppm})$ with surfactant or surfactant and polymer.

The gas blocking effect of the foams were investigated by injecting methane into the cores at a constant pressure gradients, starting off with $0,25 \mathrm{bar} / \mathrm{m}$ and increasing the pressure gradient in steps. Methane was always injected at the side of the core which had been the outlet end during foam generation, that is foam flow and methane injection were always in opposite direction. In the fixed pressure gradient experiments a volumetric pump was controlling the methane injection and another pump was located at the outlet end of the core operating in a constant pressure mode.

\section{Results and discussion}

When polymer was added to surfactant, most polymers showed reduced water film drainage in the static foam tests at ambient conditions. Our objective with this paper has been to test a few structural different polymer candidates for enhanced foam strength in core flood tests at reservoir condition.

\section{Foam formation and gas blocking, polymer enhanced foams, $110 \mathrm{bar}, 40^{\circ} \mathrm{C}, \mathrm{S}_{\mathrm{s}}=0$, Berea cores (L:29cm)}

Figure 1 shows pressure build-up during foam generation for 4 different experiments. Foam was generated by coinjecting gas and surfactant solution into the core. Two experiments were run with only AOS surfactant to test for reproducibility, while the two other experiments were run with addition of $1000 \mathrm{ppm}$ polymer (PVA or Xantan). New Berea cores were used in each experiment.

In the three experiments used to evaluate the gas blocking ability of the generated foams the foam generation time was almost equal (60-65 hours). A nearly similar pressure build-up vs. time history is observed for all experiments and addition of polymer to the aqueous phase do not seem to change the foam formation. It should be mentioned that the foams generated in these experiments are low mobility foams 
with differential pressure plateau values of about $37 \mathrm{bar}(\sim 130 \mathrm{bar} / \mathrm{m})$. During foam generation the rapid increase in pressure during the transient period significantly alter the foam quality and injection rate at the inlet end of the core. At the start of foam generation the injection rate was $41 \mathrm{ml} / \mathrm{h}$ and the foam quality was $65 \%$ (percentage gas).

The primary goal of the experiments was to evaluate if addition of polymer would improve the gas blocking ability of these water continuous foams. After completing the foam generation the core was shut-in for approximately one day to equalize the pressure drop across the core. The pressure gradient across the core was increased in steps, similar in all three experiments, starting off with $0,25 \mathrm{bar} / \mathrm{m}$. Fluid production during the experiments are shown in Figure $2 a$ and Figure $2 b$. For the foam generated without polymer the production started to increase at a pressure gradient of $4 \mathrm{bar} / \mathrm{m}(5,5$ days $)$. The best gas blocking performance was observed with foam generated with $1000 \mathrm{ppm}$ Xantan. In this experiment the production started after $\sim 30$ days. The foam had than been exposed to methane pressure gradients $\geq 4$ bar/m for 27 days. When taking into consideration the high pressure gradients, the improvement in gas blocking ability for the system with $1000 \mathrm{ppm}$ PVA compared to AOS is also significant. Another interesting observation that was made is that production rate seemed to increase gradually for the AOS and the AOS+PVA foams, while it increased in steps for the AOS+Xantan foam and the rate was then reduced to zero again after 50 days of methane injection.

\section{2a. Foam formation, polymer enhanced foams, 290 bar $100 / 70^{\circ} \mathrm{C}, S_{0}=S_{\text {org }}$, reservoir core $(\mathrm{L}: 91 \mathrm{~cm})$}

In the $91 \mathrm{~cm}$ composite reservoir core model four experiments were run at 290 bar line pressure and at 100 ${ }^{\circ} \mathrm{C}(1,2,3,4)$ and one experiment (AOS+Xantan) at 290 bar and $70{ }^{\circ} \mathrm{C}(5)$. Foam was generated by coinjecting gas and surfactant solution into the core at $40 \mathrm{ml} / \mathrm{h}$ at a foam quality of $65 \%$. Foam propagation through the core was monitored by 6 pressure ports located along the core, in addition to pressure measurements at the inlet and outlet end of the core. Prior to each foam generation, 2 PV of surfactant solution or surfactant solution and polymer was flooded through the core. Figure 3 shows the differential pressure development during foam generation with AOS. A very stable foam front was propagating at constant front rate through the core. This "piston like" appearance was observed in all five experiments. This does nor necessarily imply that foam is transported through the core, alternatively foam could be formed continuously and appear as a front that moved through the core. All five foam generation experiments gave differential pressure plateau values of about 40-50 bar across the core, which indicate generation of a low mobility foam. Calculating the pressure drop/cm across the core and comparing it with the pressure drop between each pressure tap along the core indicate that a low mobility foam is formed in every part of the core, also near the outlet end. Similar results have been observed in other studies ${ }^{6}$. Figure 4 shows the plateau pressure drop/ $\mathrm{cm}$ between each pressure tap for the five experiments.

The time needed to propagate foam through the core varied significantly in the experiments as illustrated in Figure $5 \mathrm{a}$ and Figure $5 \mathrm{~b}$. In the figures the $\mathrm{X}$-axis show normalized core position, 1 indicating the outlet end. The experiments can be divided into two groups, experiment 1 and 5 and experiment 2,3 , and 4. Prior to foam generation in experiments 1 and 5 the core had been cleaned. Oil relative permeability at irreducible water saturation was $1400 \mathrm{mD}$ before exp. 1 and $1445 \mathrm{mD}$ after cleaning before exp. 5 . In between the other experiments several pore volumes of seawater had been flooded through the core before injecting 2 PV surfactant solution or surfactant + polymer. In all experiments the differential pressure development across the core and the establishment of plateau values were used to decide when to stop foam generation. During the experiments different throughput of foam chemicals have been applied. The results show that core flood experiments that were not washed, but only flushed with synthetic seawater regenerate foam or differential pressure faster.

2b. Gas blocking, polymer enhanced foams, 290 bar $100 / 70^{\circ} \mathrm{C}, \mathrm{S}_{\mathrm{a}}=\mathrm{S}_{\text {orr }}$, reservoir core $(\mathrm{L}: 91 \mathrm{~cm})$ After completing the foam formation, the core was shut-in for approximately one day to equalize the pressure drop across the core. Methane was injected at the side of the core which was the outlet end during foam generation. Figure 6 shows the production rate versus time for experiment 1,2,3, 4, and 5 . The best gas blocking ability was observed for foam generated with AOS + Xantan. The results confirm the 
trends for Berea cores in Figure 2. This foam was able to withstand high pressure gradients as shown in Figure 7. Even after 40 days of methane injection at high pressure gradients, the production rate was below $3 \mathrm{ml} / \mathrm{h}$. The pressure gradient was increased further up to a maximum of $9 \mathrm{bar} / \mathrm{m}$ and the production rate then increased to about $400 \mathrm{ml} / \mathrm{h}$. Reducing the pressure gradient to 0.5 and $0.75 \mathrm{bar} / \mathrm{m}$ afterwards gave production rates close to zero (below $1 \mathrm{ml} / \mathrm{h}$ ) which indicate that the foam was not broken. It could be mentioned that the gas production rate, based on measurement of end point relative permeability for gas after gravity stable gas injection, would have been $4300 \mathrm{ml} / \mathrm{h}$ at a pressure gradient of only 0,25 bar/m.

Regenerated foam after flushing with seawater before exp. 2,3 and 4 gives weaker gas blocking. The foam generated in the prior experiment is not removed by flushing with synthetic seawater, Figure 5 . The properties of the resident foam clearly influences the later gas blocking results in exp. 2, 3 and 4 .

3. Formation of foam at different flow rates, $100 \mathrm{bar}, 50^{\circ} \mathrm{C}, \mathrm{S}_{\mathrm{o}}=\mathrm{S}_{\text {orz }}$, and Berea (L:29 and $\left.44 \mathrm{~cm}\right)$. Foam generation for the AOS surfactant at two different foam qualities were investigated as a function of injection rate. North Sea stock tank oil saturated with methane was present at residual oil saturation after gravity stable gas injection. Foam quality and injection rate varied in the transient period. When reaching the pressure plateau, the injection rate was either 10 or $40 \mathrm{ml} / \mathrm{h}$ and the foam quality was 65 or $90 \%$. At $65 \%$ foam quality the pressure gradient increased from 81 to $114 \mathrm{bar} / \mathrm{m}$ when the rate was increased from 10 to $40 \mathrm{ml} / \mathrm{h}$.At $90 \%$ foam quality the pressure gradient increased from 26 to $81 \mathrm{bar} / \mathrm{m}$ for similar rate increase. Larger pressure gradient is thus, obtained at low foam quality. Earlier results ${ }^{3}$ have shown even larger change in pressure gradient with foam quality in reservoir cores. The rate dependency appear to be stronger at higher foam quality.

4. Foam quality, in-situ saturations, 30 Bar, ambient temperature, $S_{0}=0$, and reservoir cores (L:29cm). In Figure 8 the saturation profiles across the core are shown for two foam qualities, $90 \%$ and $65 \%$. A seen from the figure the average water saturations in the two experiments are similar. In situ measurements of the water saturation during foam generation have been measured using $\gamma$-rays. At the start of the experiments the core was filled with AOS solution. The core was cleaned prior to each experiment and the absolute permeability to water was 1273 and $1262 \mathrm{mD}$ in the two experiments.

During foam generation the pressure plateau value is very different in the two experiments. With the $65 \%$ foam quality a plateau pressure gradient of about $21 \mathrm{bar} / \mathrm{m}$ was generated compared to about $5,5 \mathrm{bar} / \mathrm{m}$ at $90 \%$ foam quality. This means that the foam generated at $65 \%$ foam quality is a more low mobility foam. For this to be the case the amount of water participating in the foam films has to be different. The amount of free water is probably larger for the $90 \%$ foam quality foam. The possible explanation implies thicker foam lamellas at $65 \%$ foam quality which have to be compensated by thinner water films on the solid surface in order to maintain constant water saturation. Statement like, "the porous media generate its own foam quality" is in some way supported by the constant water saturation, but is again contradicted by the difference in pressure gradient at different foam qualities.

\section{Conclusions}

- Low mobility foams were generated both in Berea and reservoir core material with AOS based foams.

- The pressure ports along the core show that low mobility foam with similar properties is generated over the whole length of the core.

- The addition of polymer seems not to influence the foam formation. The pressure buildup during generation of foam is similar for AOS with or without polymer.

- Addition of polymers improved the gas blocking ability. 
- The experimental results have shown that Xantan polymer have improved the gas blocking ability of alphaolefinsulfonate foam, and can be recommended for field tests at temperatures below the thermal stability temperature of Xantan.

- In-situ saturation measurements show constant water saturation for different foam qualities indicating that the porous media may generate its own foam quality. However, the difference in pressure gradient at different foam qualities contradicts this argument.

\section{Acknowledgment}

We acknowledge Norsk Hydro ASA for permission to publish this paper.

\section{References}

1. Holm, L.W.: "The Mechanism of Gas and Liquid Flow through Porous Media in the Presence of Foam," SPEJ, 8, June 1968, 359-369.

2. Hansen, J.E., Holt, T., and Surguchev, L.M.: "Foam Processes: An Assessment of their Potential in North Sea Reservoirs based on a Critical Evaluation of Current Field Experience," SPE/DOE 27768, presented at the 9th SPE/DOE Symposium on IOR, Tulsa, Oklahoma, April 17-20, 1994, Vol.1 361-376.

3. Aarra, M.G., Skauge, A., Søgnesand.S., and Stenhaug, M.: "A Foam Pilot Test Aimed at Reducing Gas Inflow in a Production Well at the Oseberg Field", Petroleum Geoscience, Vol.2, 1996, 125-132.

4. Aarra, M.G. and Skauge, A. "A Foam Pilot in a North Sea Oil Reservoir, Preparation for a Production Well Treatment," SPE 28599, presented at the 69th Annual Technical Conference and Exhibition, New Orleans, LA. Sept. 1994, 373-385.

5. "Thin Liquid films: Fundamentals and Applications," Ivanov I.B., (ed.), Surfactant Science series, Marcel Decker, Inc., New York and Basel (1988).

6. Thach, S., Miller, K.C., and Lai, Q.J.: "Matrix Gas Shut-off in Hydraulically Fractured Wells using Polymer-Foams," SPE 36616, presented at the 1996 SPE Annual Technical Conference and Exhibition, Denver, 6-9 Oct. 1996, 443-452.

7. Sydansk, R.D.: "Polymer-Enhanced Foam Propagation through High-Permeable Sandpacks," SPE 25175, presented at the SPE International Symposium on Oilfield Chemistry, New Orleans, 2-5 March, 1993, 245-253

8. Dalland, M, and Hanssen, J.E.: "Enhanced Foams for Efficient Gas Influx Control," SPE 37217, presented at the SPE International Symposium on Oilfield Chemistry, Houston, 18-21 Febr., 1997, 71-79.

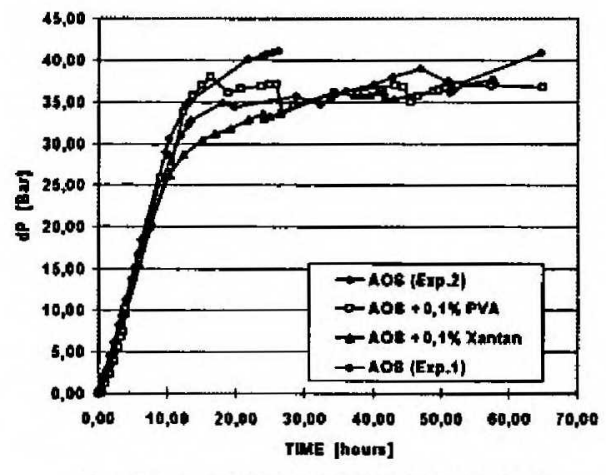

Flgure 1 foam generation at $40 \mathrm{c}, 110 \mathrm{Bar}$, Bema $\left(\mathrm{S}_{0}=0\right)$

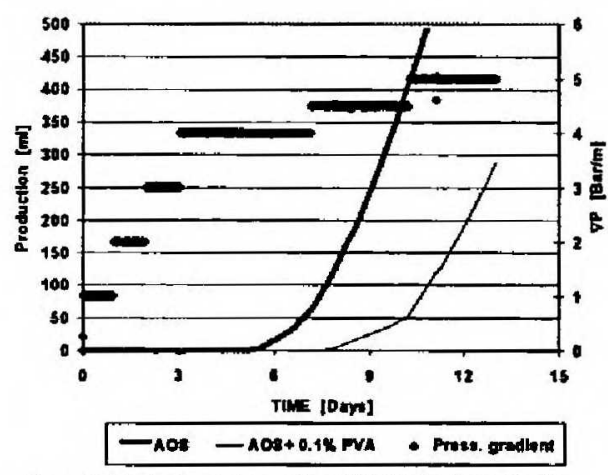

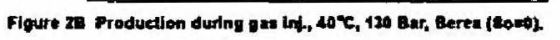

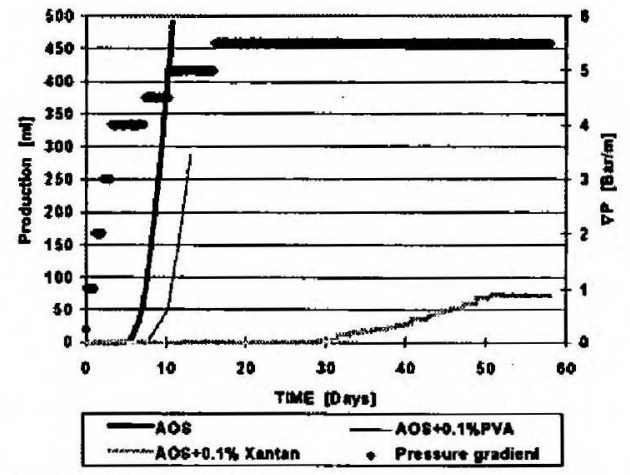

Figur 2A Production during gas Injection 400C, 130 Bur, Berea (E0 00$)$,

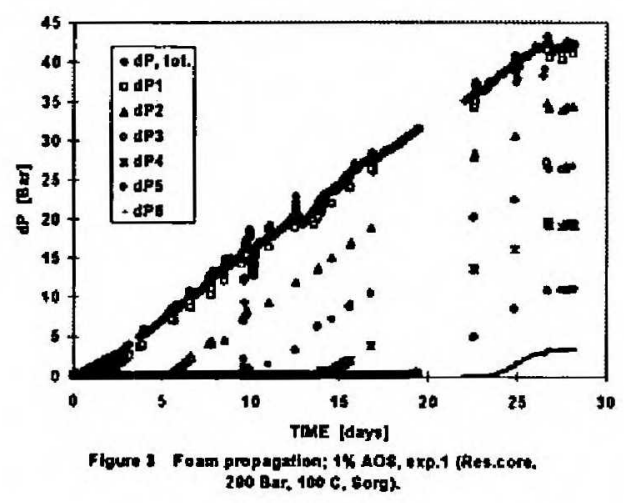




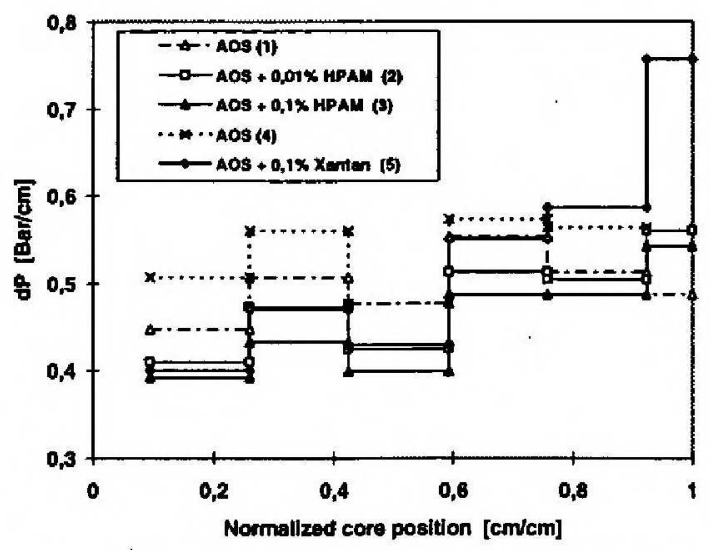

Figure 4 Preasure gradlent cm along the core at the end of loam generation ( $0=$ inlet, res.core, 290 bar, $100 / 70 \mathrm{C}$, Sorg).

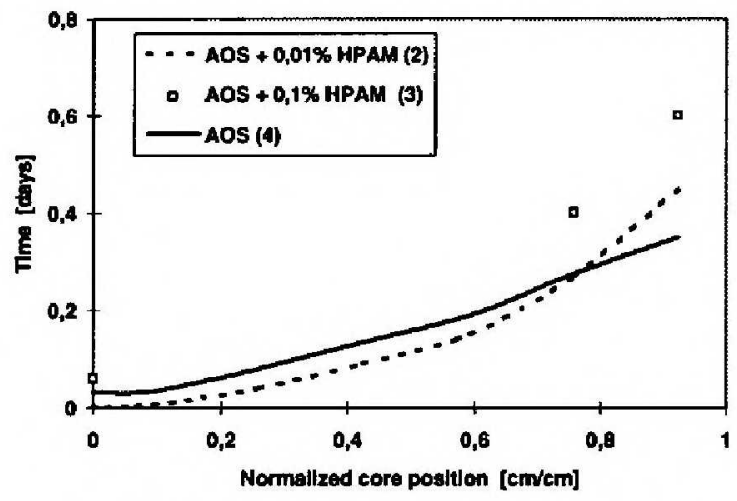

Figure $5 b$ Time for pressure bulld up to 2,5 bar alang the core (0=Inlel, res.core, 290 Bar, 100 C, Sarg).

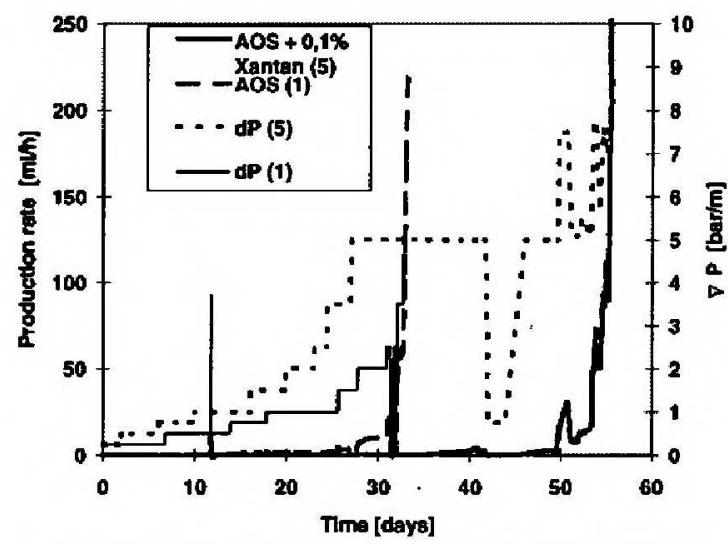

Figure 7 Production rate va. time at different pressure gradtents (res. core, 310 bar, 10070 C, Sorg).

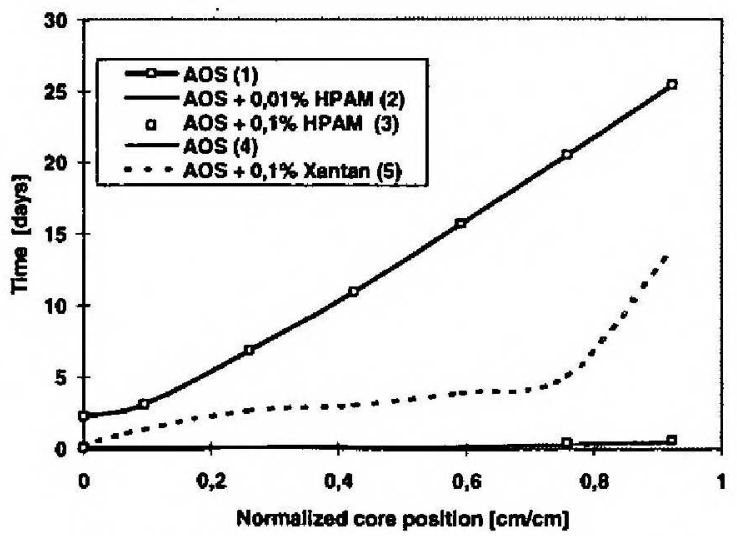

Figure 5e Time for pressure bulld up to 2,5 bar along the core (0=Inlet, res, core, 290 ber, $100770 \mathrm{C}$, Sorg)

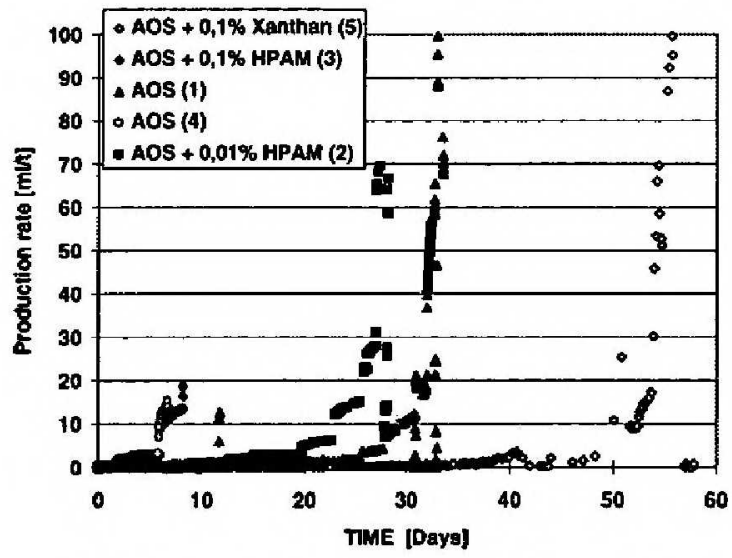

Figure 6 Production rate during gas injectlon (res.core, 310 bar, $100 / 70$ C, sorg).

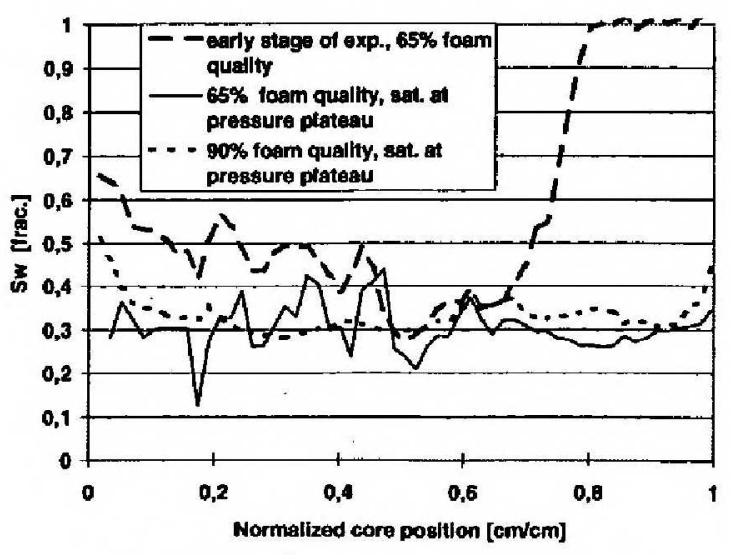

Fgure o Water saturation along the res.core (0s Inler end, AOS, 30 bar, roomtemp., So=0) 